\title{
Communicating the Probabilities of Extreme Surface Temperature Outcomes
}

\author{
Nathan Rive, Gunnar Myhre* \\ Center for International Climate and Environmental Research-Oslo (CICERO), Oslo, Norway \\ Email: "gunnar.myhre@cicero.uio.no
}

Received April 1, 2012; revised May 31, 2012; accepted June 10, 2012

\begin{abstract}
The magnitude of the future global warming is uncertain, but the possible dramatic changes associated with high temperatures have seen rising attention in the literature. Projections of temperature change in the literature are often presented in probabilistic terms and typically highlight the most likely ranges of future temperature under assumed emission scenarios. However, focusing on these high probability outcomes of global warming omits important information related to the threats of low-probability but high-impact outcomes under more extreme change. As such, we argue that the literature should place more emphasis on communicating the probabilities of extreme temperature change, in a way that is accessible to policymakers and the general public. The damage associated with climate change is likely to be non-linear with temperature, and thus extreme temperature changes may pose a larger risk than the most likely outcomes. We use a simple climate model to explore the probabilities of high surface temperature under business as usual emissions scenarios, given current knowledge of the climate system. In a business as usual scenario (A1FI) we find the probability of "likely" warming (central 66\%) to be approximately $4.4^{\circ} \mathrm{C}-6.9^{\circ} \mathrm{C}$ in 2100 (above 1900 levels). However, we find extreme $\left(>7^{\circ} \mathrm{C}\right)$ warming to embody a notable portion of damage risk compared to this likely range.
\end{abstract}

Keywords: Risk; Communication of Climate Change; Probability

\section{Introduction}

\subsection{Background}

While the potential damages are the ultimate concern, among policymakers, academics, and the general public, discussion on climate change is typically framed in terms of rising global mean surface temperature. This is because temperature is a key indicator of changes to the climate and it is familiar the general public. This is seen, most notably, in the warming limit of $2^{\circ} \mathrm{C}$ supported by the European Union [1] and recognized by the Copenhagen Accord [2]. As such, strategies for responding to the climate change are informed in part by projections of temperature change in the coming century. However, the knowledge of the climate system is incomplete and faces compounded uncertainties [3], and as such these projections usually take a probabilistic format, indicating the different likelihoods of particular temperature outcomes.

In many cases, such projections are developed via Monte Carlo-style experiments in simple climate models, capturing the uncertainty of key climate parameters such as climate sensitivity, aerosol forcing, ocean heat diffusivity and their impact on temperature change. Emissions

${ }^{*}$ Corresponding author. scenarios are run in the model over many iterations with different combinations of these parameters. The particular parameter combinations are limited to those which successfully replicate historical climate change. The resulting set of temperature projections across all these iterations is then used to construct the probability density function (PDF) of temperature outcomes over time. A number of studies have generated PDFs of future global mean temperature change (and other outcomes) under alternative business as usual $[4,5]$ and mitigation [6] emission scenarios.

The central (most probable) temperature outcomes of such projections are typically the focus in the literature. Most notably, the IPCC Fourth Assessment Report (AR4) Summary for Policymakers, presents a range of $1.1^{\circ} \mathrm{C}$ $6.4^{\circ} \mathrm{C}$ for "likely" warming to 2100 across several business as usual scenarios, where "likely" refers to the central $66 \%$ probability range [3]. Associated figures for these projections (e.g. Figure SPM.5 and 10.4 in AR4) also only show the mean values and \pm 1 standard deviation $(\sigma)$ ranges. This may be for a number of reasons: a tendency to focus on what is known best, and/or the use of specific temperature targets to guide emissions reductions. Extreme temperature outcomes, which may have very low likelihood, are often not presented. 
However, this paper argues that when communicating such analyses to the general public, the academic and summarizing literature should place more emphasis on the probabilities of extreme temperature outcomes, i.e. those with potential catastrophic impacts. The impacts of climate change are likely to be strongly non-linear with temperature change [7]. Furthermore, there is likely temperature threshold for some of the impacts of future climate change which can influence the humanity in different ways $[8,9]$. This can either be related to tipping elements in the climate system [8] or related to damages to e.g. water availability or food productivity [9]. An increased focus on the extreme temperatures by the modeling community can play an important role in how society views and responds to climate change.

The next sub-sections details the scientific context of this paper, and discuss the limitations of how temperature results are typically presented in the literature.

\subsection{Scientific Context}

Driven largely by anthropogenic emissions of greenhouse gases (GHGs), global mean surface temperature rose by approximately $0.75^{\circ} \mathrm{C}$ in the last century [3]. Future temperatures will depend on the emissions of these and other compounds affecting the radiative balance, as well as how the climate system responds to these changes $[3,10]$. Uncertainties abound, and are compounded, when future anthropogenic warming is predicted.

Climate sensitivity, defined as the equilibrium change in the global mean surface temperature from a doubling in the $\mathrm{CO}_{2}$ concentration, has large uncertainties and very high values cannot be ruled out $[3,11,12]$. Many climate feedbacks contribute to the uncertainties in the climate sensitivity and even small uncertainties in the feedbacks may be enlarged in the resulting climate sensitivity [11]. Furthermore, warming over the industrial era from anthropogenic greenhouse gases is likely masked by direct and indirect effects of anthropogenic aerosols [13-16], which could imply a high climate sensitivity [17].

As seen in the IPCC AR4 and other studies with projections of future temperature change, authors typically focus on the median or mean temperature changeswhich highlight the most likely outcomes of a particular emission scenario. Results for outer percentiles (highlighting the less likely, but more extreme temperatures) are usually available as well, e.g. the warming at the 1, 5, 95, 99 percentiles. Yet these are arguably not easily accessible to the lay-person, and generally do not make their way into the public understanding or discussion of climate change. More useful (and accessible) to the general public may be the presentation of probabilities of particular warming thresholds, which is easily extracted from the temperature PDFs. As an example, den Elzen and Meinshausen [18] highlight the probabilities of ex- ceeding $2^{\circ} \mathrm{C}$ warming under alternative stabilization scenarios. For example, they may serve to link a given emissions trajectory with the likelihood of staying below the targeted $2^{\circ} \mathrm{C}$ limit.

\subsection{Understanding and Responding to Risk}

The first weakness of focusing on the most likely ranges of temperature projects is that they may mask the risks of extreme temperature from the public understanding of climate change. Of course, the information on extreme temperature outcomes is not necessarily hidden in the literature; the 90th and 95th percentiles, or the PDFs themselves, are often presented. Yet these are not generally presented to policymakers or the general public, nor are they likely to easily extract or understand them. Studies have shown that individuals need a high degree of information and context to judge and compare low probability outcomes [19]. More transparent and accessible communication of extreme results is essential for an understanding of climate change, and could bolster arguments for greenhouse gas reductions by putting threat in context.

Secondly, focus on most likely outcomes is arguably inconsistent with how societies assess and deal with the multitude of other risks they face. Catastrophic events such as aircraft disasters, nuclear accidents, and terror attacks are not most likely outcomes, but rather probability distribution outliers. The societal response to such risk does not neglect these outliers, but rather specifically target them with sometimes costly countermeasures such as safety requirements, security screening, and counterterrorism. As such, a key question in the literature has been how society should respond to climate change, and in particular account for the outlying temperature outcomes.

This is notably relevant to the field of cost-benefit analysis, which while controversial, has been applied in numerous cases to climate change policy. Such analysis depends on expected utility (i.e. net of expected damage), and they have typically proposed more modest reductions in greenhouse gas over the coming century [20,21] compared to those under strict warming limits. Recent costbenefit literature, however, has sought to explore the implications of uncertain and possibly extreme climate change and damage [22,23]. In particular, in his Dismal Theorem, Weitzman [23] suggests that the probability density of extreme temperature change may not diminish faster than the associated (non-linear) damages_-yielding unbounded expected damages. As such, these low-probability high-impact outcomes pose difficult questions for marginal cost-benefit analysis as (in this circumstance) they could warrant vast expenditures on emissions control, and thereby offer little guidance to the public or policymakers. 
Furthermore, if society's approach to climate policy takes the form of hedging, this would require knowledge of both the likely and extreme temperature probabilities. A number of financial instruments are already in use (e.g. credit default swaps, option contracts) to hedge against loss or volatility, and additional instruments may be developed to insure against climate damages if particular thresholds are exceeded [24]. Alternatively, climate change hedging may take the form of emissions reductions targeted specifically at reducing the possibilities of reaching key (potentially catastrophic) warming thresholds in future [25], or ensuring future climate targets remain within reach [26].

\subsection{Communicating Extreme Temperatures and Risks}

Given its importance to society's understanding and response to climate change, how, then, can the probabilities of extreme temperature change be calculated and communicated by researchers? There is, of course, no one correct answer. Instead, we are advocating "good practice" among climate modelers: presenting both the likely and more extreme temperature outcomes of model projections, and seeking to do so in a way that is transparent and accessible to general public and policymakers. Several examples are discussed below, but this list is by no means exhaustive.

A useful means of presenting extreme warming probabilities is to focus on the probabilities of exceeding key warming thresholds (e.g. the $2^{\circ} \mathrm{C}$ limit). Anchoring the results to particular temperature levels is arguably more accessible to the layman than focusing on the probabilities themselves (e.g. the top decile warming range), as such temperatures can form the basis of particular climate goals or be associated with particular climate impacts to the environment and economy. This could include risks of species extinction, coral bleaching, reduced agricultural productivity under $2^{\circ} \mathrm{C}-3^{\circ} \mathrm{C}$ warming $[27$, Figure SPM.2]. This does not require the development of new methodologies per se, and in principle such a perspective could be applied in most of the existing probabilistic studies found in the literature.

\section{Illustrative Modeling Exercise}

As a means of supporting the above arguments, a modeling exercise is undertaken here to illustrate the probabilities of large temperature changes in 2050 and 2100 under alternative business as usual scenarios- the IPCC SRES A1B, A1FI, and A2 marker scenarios [28]. These scenarios represent alternative emissions trajectories that are unconstrained by climate policy under differing socio-economic and technological trends. The emissions scenarios are run in a simple climate model (SCM), in a
"What's the worst that could happen?" examination of unabated greenhouse gas emissions growth and potential temperature outcomes of that growth [29], and in particular the probability distribution of the temperature outcomes. The A1FI is the most "pessimistic" of the scenarios, with the highest cumulative emissions to 2100 , although it appears to best represent recent global emissions trends [30].

In line with the "good practice" highlighted above, alongside the most likely temperature outcome of these scenarios we focus on two aspects of the more extreme potential temperature changes: 1) the probabilities of exceeding key warming thresholds, and 2) the risks associated with extreme warming. While the methodologies are largely line with existing techniques found in the literature, our focus on the high temperature results is novel.

With regards to temperature thresholds, we explore the probabilities of exceeding $2^{\circ} \mathrm{C}, 2.5^{\circ} \mathrm{C}$, and $3^{\circ} \mathrm{C}$ warming (above 1900 levels) in 2050 , and $5^{\circ} \mathrm{C}, 6^{\circ} \mathrm{C}$, and $7^{\circ} \mathrm{C}$ in 2100. The results are shown for various temperature thresholds since different temperature changes may be responsible for different impacts [27, Figure SPM.2]. Because these temperature changes are expected to yield damages to the economy and environment, they can be presented in terms of the risks that they effectively pose. In particular, we can compare the risks posed by the more extreme temperature outcomes (which may be less likely, but result in large damages) to the risks posed by the more moderate temperature outcomes (which may be more likely, but with lesser damages). In this exercise we do this by comparing each ranges' contribution $(C)$ to the overall expected damages. This contribution is a simple representation of risk, and is defined as:

$$
C\left(t_{1}, t_{2}\right)=\frac{\int_{t_{1}}^{t_{2}} p(\Delta T) D(\Delta T) \mathrm{d} \Delta T}{\int_{-\infty}^{\infty} p(\Delta T) D(\Delta T) \mathrm{d} \Delta T}
$$

$\Delta T$ represents global mean surface temperature change, assuming some future emissions trajectory and time period. The variables $p(\Delta T)$ and $D(\Delta T)$ represent the associated probability density and climate impact damage; $t_{1}$ and $t_{2}$ are the temperature ranges of concern (e.g. extreme or most likely ranges).

The CICERO Simple Climate Model (SCM) is employed [31], used previously in several studies $[32,33]$. This model simulates global mean temperature change by an energy-balance climate/up-welling diffusion ocean model developed by Schlesinger et al. [34]. Climate sensitivity and parameters which control the uptake of heat by the oceans, are set exogenously, which govern the climate response [35]. Historical emissions are taken from publicly available databases [36,37]. Global mean concentrations are calculated from emissions data and 
radiative forcing is calculated using concentration-forcing relations from IPCC AR4 [13]. $\mathrm{CO}_{2}$ concentrations are calculated using a scheme based on Joos et al. [38]. Where data is available, historical volcanic and solar forcings are included. The model has recently been used in another study where the climate sensitivity has been derived the historical temperature record over last century in a Bayesian framework [39].

Two approaches are adopted to calculate the probabilities of surface temperatures changes. The aim is to mirror their parallel use in the literature, and demonstrate how methodological differences can impact the estimated probabilities of extreme outcomes. The first approach (labeled as "Feasible") employs a Monte Carlo experiment, running the scenarios multiple times under alternative model parameter assumptions, and constraining the results by historical warming observations. Alternative values of both climate sensitivity and aerosol forcing are sampled from assumed prior probability distributions, in a similar vein to other studies in the literature $[4,17,40]$.

Latin Hypercube Sampling (LHS) is used with a sample size of 15,000. Prior probabilities for each parameter are broken into equal probability segments, with each segment randomly sampled only once. Values for indirect sulphate forcing (uniform distribution) and direct aerosol forcing (normal distribution) priors are taken from AR4 (Table 2.12 in Chapter 2). The prior for climate sensitivity is assumed to take a Cauchy distribution based (in part) on earlier expert opinion [41] ${ }^{1}$. See Table $\mathbf{1}$ below for the listing of these assumptions. Historical El Nino-Southern Oscillation (ENSO), solar forcing, and volcanic eruptions are accounted for. Each model run is weighted by its replication of historical (1851-2005) global mean surface temperature observations [42], assuming a first-order autoregressive model and normally distributed error $[43,44]$. This weighting is then applied to these parameter combinations and the associated temperature projections via weighted kernel density estimation, to generate posterior probability distributions of these key climate parameters and temperature change outcomes. The results of this approach (both temperature outcomes and risks) are presented in the next section.

The second approach (labeled as "Best Estimate") treats the uncertainties of aerosol and climate sensitivity separately. While it is not as comprehensive as the Feasible approach, it is seen elsewhere in the literature [18,33]. The model is only run using most likely values for aerosol forcing; for consistency these are taken from posterior PDFs developed under the Feasible approach. The probabilities of exceeding each threshold are calculated via an "nverse lookup" of the posterior PDF of climate sensitivity (also developed under the Feasible approach). Specifically, the model is run (with best estimate aerosol

${ }^{1}$ Truncated at $0^{\circ} \mathrm{C}$ and $20^{\circ} \mathrm{C}$ per doubling of $\mathrm{CO}_{2}$ concentration. forcings) iteratively to find the equilibrium climate sensitivity levels that yield each respective temperature threshold level. For example, it is found that a climate sensitivity of $3.0^{\circ} \mathrm{C}$ will yield $2^{\circ} \mathrm{C}$ warming (above 1900 levels) in 2050 under the A1B scenario. The cumulative probability (and thus the probability of exceedance) of this climate sensitivity level is then looked up on the posterior PDF. These Best Estimate model results are also presented and discussed in the next section.

\section{Analysis of Modeling Results}

\subsection{Temperature Changes}

Figure 1 presents probabilistic temperature change over the period 2000-2100 for the SRES A1FI scenario under the Best Estimate and Feasible approaches. The central $66 \%$ (likely) probability range and median warming in the A1FI scenario are approximately $4.4^{\circ} \mathrm{C}-6.9^{\circ} \mathrm{C}$ and $5.6^{\circ} \mathrm{C}$ (above 1900 levels) respectively under both approaches. However, the central $90 \%$ range is notably wider under the Best Estimate approach. This is because it allows for combinations of high climate sensitivity and weak aerosol forcing (and vice versa) that would be rejected (i.e. given a low weighting) in the Feasible approach, as they would poorly replicate historical warming.

\subsection{Probabilities of Threshold Exceedance}

The probabilities of exceeding key temperature thresholds in 2050 and 2100 under the SRES scenarios is presented in Figure 2. The first striking result is that $2^{\circ} \mathrm{C}$, a key threshold for the European Union and Copenhagen Accord, is reached with more than $55 \%$ probability in all these three scenarios in 2050. Under A1FI, the probability is approximately $90 \%$. Concerns have already been raised over the adequacy of current commitments seeking to limit warming below $2^{\circ} \mathrm{C}$ [45].

For more extreme temperature levels in 2100 , the results may be equally worrying. The probabilities of reaching $5^{\circ} \mathrm{C}$ warming by 2100 are substantial—between

Table 1. Prior probability distributions for model parameters in Feasible approach. Forcing taken to be change in forcing between 1750-2005. Climate sensitivity is taken to be ${ }^{\circ} \mathrm{C}$ per doubling of $\mathrm{CO}_{2}$ concentration at equilibrium.

\begin{tabular}{ccccc}
\hline Model Parameter & Units & $\begin{array}{c}\text { Prior } \\
\text { Distribution }\end{array}$ & $\begin{array}{c}\text { Distribution } \\
\text { Parameters }\end{array}$ & Source \\
\hline $\mathrm{SO}_{4}$ Forcing (direct) & $\mathrm{W} / \mathrm{m}^{2}$ & Normal & $\mu:-0.4, \sigma: 0.12$ & {$[13]$} \\
$\mathrm{SO}_{4}$ Cloud Effect & $\mathrm{W} / \mathrm{m}^{2}$ & Uniform & $\begin{array}{c}\text { range: } \\
-1.9 \text { to }-0.22\end{array}$ & {$[13]$} \\
Black Carbon & $\mathrm{W} / \mathrm{m}^{2}$ & Normal & $\mu: 0.2, \sigma: 0.09$ & {$[13]$} \\
$\begin{array}{c}\text { Forcing (direct) } \\
\text { Organic Carbon }\end{array}$ & $\mathrm{W} / \mathrm{m}^{2}$ & Normal & $\mu:-0.05, \sigma: 0.03$ & {$[13]$} \\
Forcing (direct) & & & & \\
Climate Sensitivity & ${ }^{\circ} \mathrm{C}$ & Cauchy & loc: 2, scale: 3.5 & {$[41]$} \\
\hline
\end{tabular}




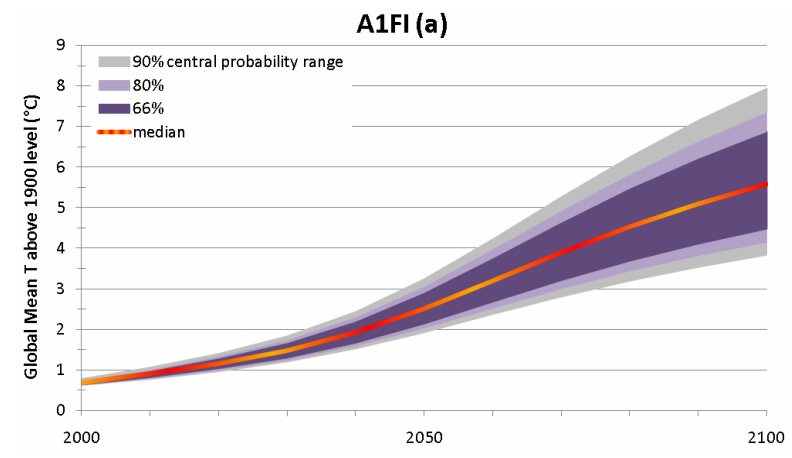

(a)

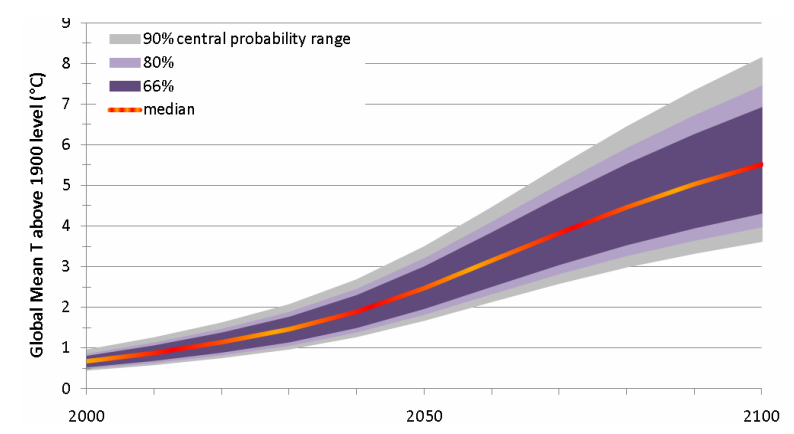

(a)

Figure 1. Probabilistic temperature change in the 21st century (above 1900 levels) under SRES A1FI scenarios, calculated using the (a) feasible and (b) best estimate approaches.

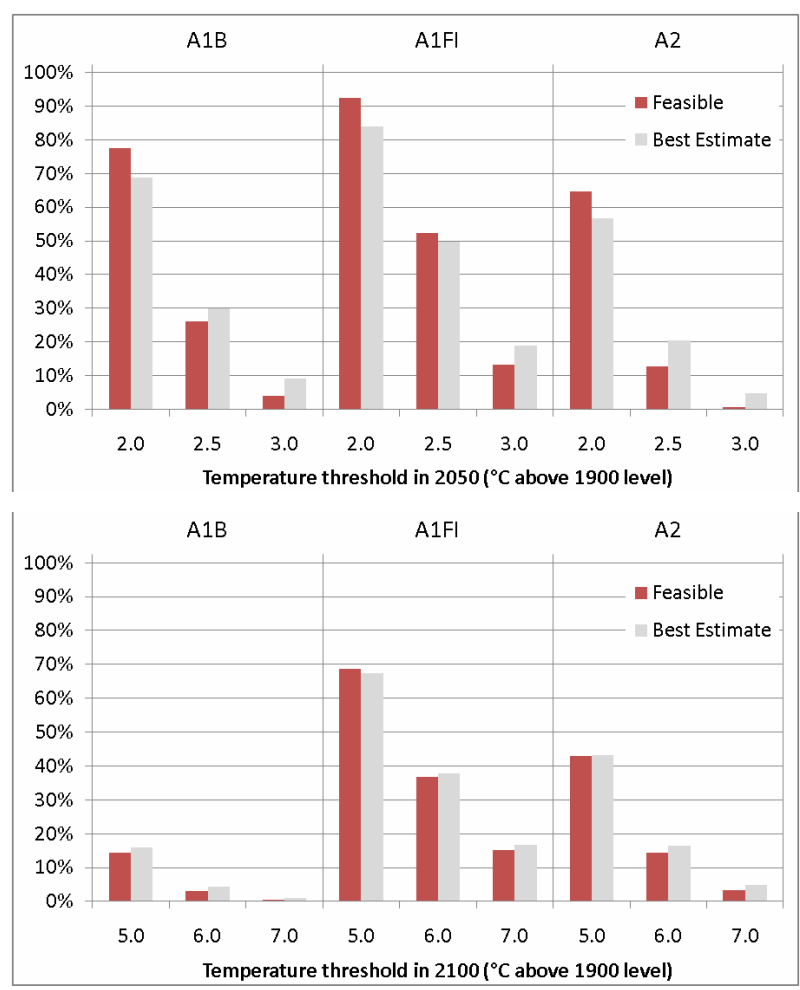

Figure 2. Probabilities of temperature exceedance in 2050 and 2100 under alternative scenarios and calculation approaches. approximately $15 \%$ and $65 \%$ depending on the approach and scenario. Such a warming could have catastrophic consequences, and these relatively high probabilities need to be highlighted to the general public. The probabilities of reaching $6^{\circ} \mathrm{C}$ and $7^{\circ} \mathrm{C}$ under the A1FI scenarios of approximately $35 \%$ and $15 \%$ respectively show that even more extreme temperatures may be reached relatively easily (given the severity of potential impacts) under our current "business as usual" trends. The A1B scenario, which sees reductions in greenhouse gases after 2050 has much lower (or negligible) probabilities of these warming levels.

\subsection{Associated Risks}

As indicated in Equation (1) above, exploring the risks associated with temperature change requires assumptions about the relationship between temperature change $(\Delta T)$ and the consequent impacts $(D(\Delta T))$. In the integrated assessment modeling literature, climate impacts are often represented by a damage function with the form:

$$
D(\Delta T)=a(\Delta T)^{x}
$$

It is a heavy simplification of the temperature-impact relationship, and we know little about the possible form and parameters of such a function. However, this particular functional form is common, having been used by e.g. Nordhaus and Boyer [20] and Stern [46], and is useful in this context to illustrate our argument. For our example, $D$ is given in arbitrary units, and can represent any manner of losses: global consumption, utility, human life and ecosystem loss. The scale term $a$ may be calibrated using empirical data, but is assumed here to be unity. The exponent term $x$ is typically set to 2 to 3 in the literature to capture the non-linearities of impacts. However, these are assumptions made on the basis of limited information about the impacts of climate change; lower and higher values (1 to 5) have also been explored [22].

We combine the risk measure presented in Equation1 with the above damage function and our temperature change PDFs of the SRES scenarios. For the A1FI scenario, Figure 3 presents the risks associated with the likely and top quintile and decile temperature changes in 2100 , under alternative damage exponents $(x)$. For the typical damage exponents used in the literature $(x=2$ to 3 ), the likely range holds the majority of the risk. However, the extreme tails also a large and important share of the risk (roughly $50 \%-75 \%$ and $30 \%-40 \%$ the size of the likely range risk). At higher exponents $(x>4)$, the risk associated with the top quintile overtakes that of the likely range ${ }^{2}$. This suggests potentially large risks are being missed under a focus of the central estimates of temperature change. The size of these risks depends on

\footnotetext{
${ }^{2}$ The results for the $\mathrm{A} 1 \mathrm{~B}$ and $\mathrm{A} 2$ scenarios are approximately the same.
} 


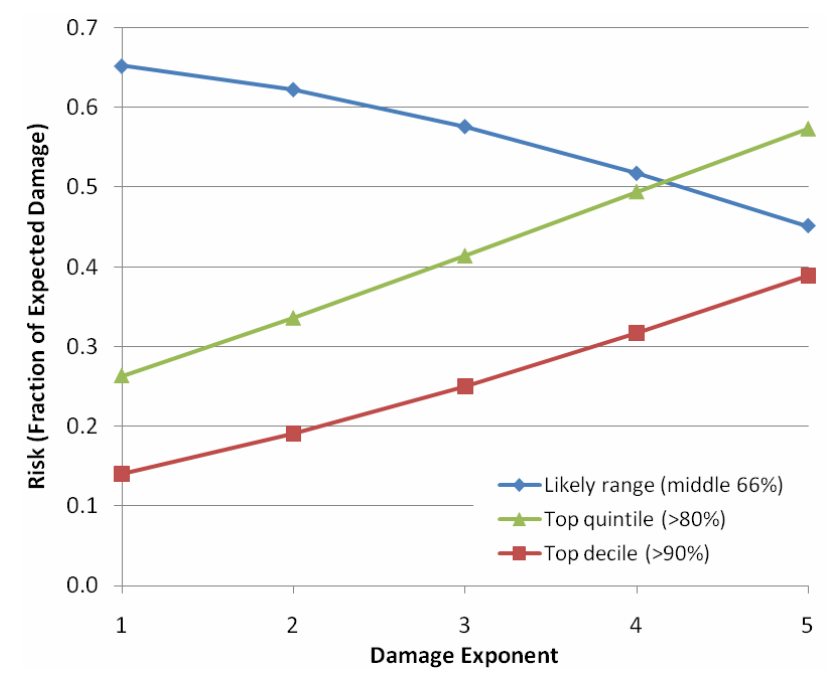

Figure 3. Risk (measured as the contribution to expected damage, see Equation (1) from likely and "extreme" ranges of temperature change in 2100 under the A1FI scenario. Damage function is taken from Equation (2) above.

the shape of the temperature PDF and the damage function assumptions. If our temperature PDF had a "fatter" right-hand tail (i.e. higher likelihood of extreme temperature change), or if the damage function accounted for larger damages at higher temperature (e.g. irreversible singular events), the risks of extreme temperatures compared to the most likely outcomes would be even larger.

\section{Caveats and Challenges}

It goes without saying that we have not presented an exhaustive picture of how extreme temperatures should be discussed in the literature. A key hurdle remains with respect to how they can be calculated. The paradox, of course, is that we are advocating an increased focus on outcomes of which we are least certain. Probabilistic results will depend heavily on the applied model, methodologies and assumptions, and subjectivities. The hope, is that over time the literature will have developed a range of the probabilities of extreme outcomes, in the same way that "likely" ranges have been presented (e.g. in the IPCC AR4).

Neither have we offered a solution to how policymakers would then use such information to formulate a response. Individuals (and societies) are often poor evaluators of risk, particularly with respect to low-probability high-impact outcomes [19], and policy responses to threats are rarely consistent. One example of such an inconsistency is the "One Percent Doctrine" applied by the Bush Administration towards terrorism, by which a $1 \%$ chance of a low-probability high-impact event (e.g. acquisition of nuclear bomb by al-Qaeda) was to be acted upon as if it were certain to occur [47]. It goes without saying that the Administration's climate change policy did not feature the same approach. Furthermore, alongside to the damage risks, we should in principle consider the mitigation risks; mitigation may turn out to be more expensive or disruptive than expected. Or there may be a policy overreaction with excessive (costly) mitigation. Such "action bias" is highly relevant to climate change given potentially emotional responses to what may be at stake [48].

\section{Conclusions}

In this paper, we argue that for the general public's (and policymakers') consideration of climate change, the probability of extreme warming is key information that is often missing in the public debate. Extreme temperature change outcomes, even if they have low likelihood of occurring, pose a large risk compared to the likely ranges, which needs to be highlighted. However, the likelihood of these extremes has tended to be under-represented in the modeling literature.

The method outlined here can be improved by either physical parameters important for the simple climate model [49] or improved work on the radiative forcing time series [50]. However, the results outlined here can also be derived from a larger set of Atmospheric Ocean General Circulation Models (AOGCMs) or ensemble simulations in one AOGCM [12]. Thus, the main emphasis of this study on extreme temperature outcomes and associated risks can be derived by various methods and model complexities.

The extreme temperature probabilities can play a key role in shaping public attitudes to climate change and the development of responses. Knowledge of these extremes may directly inform the development of climate change mitigation policy, including those based on cost-benefit analysis and hedging strategies. We advocate for "good practice" among climate modelers to better communicate the probabilities of extreme outcomes alongside the most likely temperature ranges.

The paper supports these arguments using an illustrative modeling exercise to highlight the probabilities of exceeding key temperature thresholds by 2100 . Under the SRES A1FI scenario in 2100 , there is a notable probability $(>60 \%)$ of exceeding $5^{\circ} \mathrm{C}$, whereas the central $66 \%$ probability range is approximately $4.4^{\circ} \mathrm{C}-6.9^{\circ} \mathrm{C}$. Likewise the probability to exceed $6^{\circ} \mathrm{C}$ in this scenario is $35 \%-40 \%$ and more than $15 \%$ to exceed $7^{\circ} \mathrm{C}$. What the results suggest is the surprising ease by which a business as usual can lead to extreme temperatures in future, a point that has been under-reported in the summarizing and scientific literature so far.

\section{Acknowledgements}

The authors thank Katsumasa Tanaka for comments and 
collaboration on the modeling methodology. This work was funded in part by the Norwegian Research Council (NFR) Strategic Institute Program.

\section{REFERENCES}

[1] European Commission, "Decision of the European Parliament and of the Council on the Effort of Member States to Reduce Their Greenhouse Gas Emissions to Meet the Community's Greenhouse Gas Emission Reduction Commitments up to 2020," 2008.

[2] UNFCCC, "Draft decision-/CP.15: Copenhagen Accord," Conference of Parties, Copenhagen, 2009.

[3] IPCC, "The Physical Science Basis. Contribution of Working Group I to the Fourth Assessment Report of the Intergovernmental Panel on Climate Change," Cambridge University Press, Cambridge, 2007.

[4] R. Knutti, T. F. Stocker, F. Joos and G. K. Plattner, "Probabilistic Climate Change Projections Using Neural Networks," Climate Dynamics, Vol. 21, No. 3-4, 2003, pp. 257-272. doi:10.1007/s00382-003-0345-1

[5] T. M. L. Wigley and S. C. B. Raper, "Interpretation of High Projections for Global-Mean Warming," Science, Vol. 293, No. 5529, 2001, pp. 451-454. doi:10.1126/science.1061604

[6] M. Meinshausen, et al., "Greenhouse-Gas Emission Targets for Limiting Global Warming to 2 Degrees C," $\mathrm{Na}$ ture, Vol. 458, No. 7242, 2009, pp. 1158-1162. doi:10.1038/nature 08017

[7] R. S. J. Tol, "The Economic Effects of Climate Change," Journal of Economic Perspectives, Vol. 23, No. 2, 2009, pp. 29-51. doi:10.1257/jep.23.2.29

[8] T. M. Lenton, et al., "Tipping Elements in the Earth's Climate System," Proceedings of the National Academy of Sciences of the United States of America, Vol. 105, No. 6, 2008, pp. 1786-1793. doi:10.1073/pnas.0705414105

[9] M. L. Parry, O. F. Canziani, J. P. Palutikof and Co-Authors, "Technical Summary. Climate Change 2007: Impacts, Adaptation and Vulnerability," In: M. L. Parry, et al., Eds., Contribution of Working Group II to the Fourth Assessment Report of the Intergovernmental Panel on Climate Change, Cambridge University Press, Cambridge, 2007.

[10] J. Hansen, et al., "Dangerous Human-Made Interference with Climate: A GISS Modele Study," Atmospheric Chemistry and Physics, Vol. 7, No. 9, 2007, pp. 2287-2312. doi:10.5194/acp-7-2287-2007

[11] G. H. Roe and M. B. Baker, "Why Is Climate Sensitivity So Unpredictable?” Science, Vol. 318, No. 5850, 2007, pp. 629-632. doi:10.1126/science. 1144735

[12] D. A. Stainforth, et al., "Uncertainty in Predictions of the Climate Response to Rising Levels of Greenhouse Gases," Nature, Vol. 433, No. 7024, 2005, pp. 403-406. doi:10.1038/nature03301

[13] P. Forster, et al., "Changes in Atmospheric Constituents and in Radiative Forcing, in Climate Change 2007: The Physical Science Basis," In: S. Solomon, et al., Eds., Contribution of Working Group I to the Fourth Assess- ment Report of the Intergovernmental Panel on Climate Change, Cambridge University Press, Cambridge, 2007.

[14] J. Hansen, et al., "Earth's Energy Imbalance: Confirmation and Implications," Science, Vol. 308, No. 5727, 2005, pp. 1431-1435. doi:10.1126/science.1110252

[15] Y. J. Kaufman, D. Tanre and O. Boucher, "A Satellite View of Aerosols in the Climate System," Nature, Vol. 419, No. 6903, 2002, pp. 215-223. doi:10.1038/nature01091

[16] G. Myhre, "Consistency between Satellite-Derived and Modeled Estimates of the Direct Aerosol Effect," Science, Vol. 325, No. 5937, 2009, pp. 187-190. doi:10.1126/science. 1174461

[17] M. O. Andreae, C. D. Jones and P. M. Cox, "Strong Present-Day Aerosol Cooling Implies a Hot Future," Nature, Vol. 435, No. 7046, 2005, pp. 1187-1190. doi:10.1038/nature03671

[18] M. G. J. den Elzen and M. Meinshausen, "Multi-Gas Emission Pathways for Meeting the EU $2^{\circ} \mathrm{C}$ Climate Target in Avoiding Dangerous Climate Change," Cambridge University Press, Cambridge, 2006.

[19] H. Kunreuther, N. Novemsky and D. Kahneman, "Making Low Probabilities Useful," Journal of Risk and Uncertainty, Vol. 23, No. 2, 2001, pp. 103-120. doi:10.1023/A:1011111601406

[20] W. D. Nordhaus and J. Boyer, "Warming the World: Economic Models of Global Warming," Cambridge University Press, Cambridge, 2000.

[21] R. S. J. Tol, "On the Optimal Control of Carbon Dioxide Emissions: An Application of FUND," Environmental Modeling and Assessment, Vol. 2, No. 3, 1997, pp. 151163. doi:10.1023/A:1019017529030

[22] F. Ackerman, E. A. Stanton and R. Bueno, "Fat Tails, Exponents, Extreme Uncertainty: Simulating Catastrophe in DICE," Ecological Economics, Vol. 69, No. 8, 2010, pp. 1657-1665. doi:10.1016/j.ecolecon.2010.03.013

[23] M. L. Weitzman, "On Modeling and Interpreting the Economics of Catastrophic Climate Change," Review of Economics and Statistics, Vol. 91, No. 1, 2009, pp. 1-19. doi:10.1162/rest.91.1.1

[24] H. C. Kunreuther and E. O. Michel-Kerjan, "The Development of New Catastrophe Risk Markets," Annual Review of Resource Economics, Vol. 1, 2009, pp. 119-137.

[25] M. L. Weitzman, "GHG Targets as Insurance agains Catastrophic Climate Damages," Harvard University, Cambridge, 2009.

[26] G. Yohe, N. Andronova and M. Schlesinger, "ClimateTo Hedge or Not against an Uncertain Climate," Science, Vol. 306, No. 5695, 2004, pp. 416-417. doi:10.1126/science. 1101170

[27] IPCC, "Summary for Policymakers, in Climate Change 2007: Impacts, Adaptation and Vulnerability," In: M. L. Parry, et al., Eds., Contribution of Working Group II to the 4th Assessment Report of the Intergovernmental Panel on Climate Change, Cambridge University Press, Cambridge, 2007, p. 16.

[28] N. Nakicenovic and R. Swart, "Special Report of Working Group III of the Intergovernmental Panel on Climate 
Change," Cambridge Univeristy Press, Cambridge, 2000.

[29] S. Schneider, "The Worst-Case Scenario," Nature, Vol. 458, No. 7242, 2009, pp. 1104-1105. doi:10.1038/4581104a

[30] G. Myhre, K. Alterskjaer and D. Lowe, "A Fast Method for Updating Global Fossil Fuel Carbon Dioxide Emissions," Environmental Research Letters, Vol. 4, No. 3, 2009, Article ID: 034012. doi:10.1088/1748-9326/4/3/034012

[31] J. S. Fuglestvedt and T. Berntsen, "A Simple Model for Scenario Studies of Changes in Global Climate: Version $1.0, " 1999$.

[32] J. S. Fuglestvedt, et al., "Metrics of Climate Change: Assessing Radiative Forcing and Emission Indices," Climatic Change, Vol. 58, No. 3, 2003, pp. 267-331. doi:10.1023/A:1023905326842

[33] N. Rive, A. Torvanger, T. Berntsen and S. Kallbekken, "To What Extent Can a Long-Term Temperature Target Guide Near-Term Climate Change Commitments?" Climatic Change, Vol. 82, No. 3-4, 2007, pp. 373-391. doi:10.1007/s10584-006-9193-4

[34] M. Schlesinger, M. E. Jiang and R. J. Charlson, "Implication of Anthropogenic Atmospheric Sulphate for the Sensitivity of the Climate System," Proceedings of the International Conference on Global Climate Change, New York, 1992.

[35] D. Harvey, et al., "An Introduction to Simple Climate Models Used in the IPCC Second Assessment Report," 1997.

[36] European Commissionand Joint Research Centre, "Emission Database for Global Atmospheric Research (EDGAR), Release Version 4.0," 2009.

[37] T. Boden, G. Marland and R. J. Andres, "National $\mathrm{CO}_{2}$ Emissions from Fossil-Fuel Burning, Cement Manufacture, and Gas Flaring: 1751-2006," 2009.

[38] F. Joos, et al., "An Efficient and Accurate Representation of Complex Oceanic and Biospheric Models of Anthropogenic Carbon Uptake," Tellus Series B-Chemical and Physical Meteorology, Vol. 48, No. 3, 1996, pp. 397-417. doi:10.1034/j.1600-0889.1996.t01-2-00006.x

[39] M. Aldrin, et al., "Bayesian Estimation of Climate Sensitivity Based on a Simple Climate Model Fitted to Observations of Hemispheric Temperatures and Global Ocean
Heat Content," Environmetrics, Vol. 23, No. 3, 2012, pp. 253-271. doi:10.1002/env.2140

[40] A. P. Sokolov, et al., "Probabilistic Forecast for TwentyFirst-Century Climate Based on Uncertainties in Emissions (without Policy) and Climate Parameters," Journal of Climate, Vol. 22, No. 19, 2009, pp. 5175-5204. doi:10.1175/2009JCLI2863.1

[41] J. D. Annan and J. C. Hargreaves, "On the Generation and Interpretation of Probabilistic Estimates of Climate Sensitivity," Climatic Change, Vol. 104, No. 3-4, 2011, pp. 423-436. doi:10.1007/s10584-009-9715-y

[42] P. Brohan, J. J. Kennedy, I. Harris, S. F. B. Tett and P. D. Jones, "Uncertainty Estimates in Regional and Global Observed Temperature Changes: A New Data Set from 1850," Journal of Geophysical Research-Atmospheres, Vol. 111, No. D12, 2006, Article ID: D12106. doi:10.1029/2005JD006548

[43] E. Kriegler, "Imprecise Probability Analysis for Integrated Assessment of Climate Change," Potsdam University, Potsdam, 2005.

[44] H. von Storch and F. W. Zwiers, "Statistical Analysis in Climate Research," Cambridge University Press, Cambridge, 2002.

[45] J. Rogelj, et al., "Copenhagen Accord Pledges Are Paltry," Nature, Vol. 464, No. 7292, 2010, pp. 1126-1128. doi: $10.1038 / 4641126 \mathrm{a}$

[46] Stern, "The Economics of Climate Change: The Stern Review," 2006.

[47] R. Suskind, "The One Percent Doctrine: Deep Inside America's Pursuit of Its Enemies Since 9/11," Simon \& Schuster, New York, 2006.

[48] C. R. Sustein and R. Zeckhauser, "Overreaction to Fearsome Risks," Environmental Resource Economics, in Press.

[49] D. Olivie and N. Stuber, "Emulating AOGCM Results Using Simple Climate Models," Climate Dynamics, Vol. 35, No. 7-8, 2010, pp. 1257-1287. doi:10.1007/s00382-009-0725-2

[50] R. B. Skeie, et al., "Anthropogenic Radiative Forcing Time Series from Pre-Industrial Times until 2010," Atmospheric Chemistry and Physics, Vol. 11, No. 22, 2011, pp. 11827-11857. 